\title{
Retraction Note to: Variographic analysis of chemical and piezometric data from the sandstone aquifer of Ain Oussera, Algeria
}

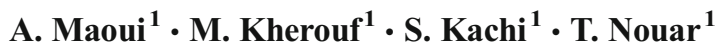

Published online: 16 September 2017

(C) Saudi Society for Geosciences 2017

Retraction Note to: Arab J Geosci (2013) 6:1307-1324

https://doi.org/10.1007/s12517-011-0422-4

This article (Maoui et al. 2013) has been retracted by the Editor-in-Chief in consultation with the Publishing Editor, because parts of the Abstract, Introduction, Methodology, Fig. 4, and Conclusions were duplicated from a previously published article by Saibi et al. (2009). All authors agree to this retraction.

\section{References}

Maoui A, Kherouf M, Kachi S, Nouar T (2013) Variographic analysis of chemical and piezometric data from the sandstone aquifer of Ain Oussera, Algeria. Arab J Geosci 6:1307-1324. https://doi.org/10. 1007/s12517-011-0422-4

Saibi H, Semmar A, Mesbah M, Ehara S (2009) Variographic analysis of water table data from the Oued-Souf phreatic aquifer, northeastern part of the Algerian Sahara. Arab J Geosci 2:83-93. https://oi.org/ 10.1007/s12517-008-0021-1

The online version of the original article can be found at https://doi.org/ 10.1007/s12517-011-0422-4

A. Maoui

maoui_ammar@yahoo.fr

Laboratory of Civil Engineering and Hydraulic (LCGH), University of Guelma, BP 401, 24000 Guelma, Algeria 